342 injections $\left(38^{\circ}{ }_{0}\right)$ in the placebo group; the higher incidence of local reactions in the placebo group was statistically significant $(P<0.01)$. During the initial course of six injections seven patients in the vaccine group and five in the placebo group developed wheeze and dyspnoea within 48 hours of an injection. These episodes were mild, but at the next weekly visit a second injection of the same strength of vaccine (or matching placebo) was given, usually without ill effect, and the course was resumed at the following visit.

Skin and nasal challenge tests-Initital sensitivities are shown in table III. Sensitivity was considered to have decreased when a higher strength of $D$ pteronyssinus extract was required to provoke a positive reaction and increased when a lower strength of test solution was required. In both vaccine and placebo groups some patients showed a decrease in skin or nasal sensitivity, or both, others an increase, and others no change. There was no significant difference in skin or nasal sensitivity between the two groups at any assessment period.

TABLE III-Number of patients responding to skin and nasal challenge tests with extract of $\mathrm{D}$ pteronyssinus before treatment

\begin{tabular}{|c|c|c|c|c|c|c|c|c|}
\hline & & \multicolumn{4}{|c|}{ Skin test } & \multicolumn{3}{|c|}{ Nasal challenge } \\
\hline & & $0.005 \%$ & $0.04 \%$ & $0.33 \%$ & $1.2 \%$ & $0.005 \%$ & $0.04 \%$ & $0.33 \%$ \\
\hline $\begin{array}{l}\text { Vaccine group } \\
\text { Placebo group }\end{array}$ & $\therefore$ & $\begin{array}{l}7 \\
13\end{array}$ & $\begin{array}{r}13 \\
8\end{array}$ & $\begin{array}{l}4 \\
7\end{array}$ & $\begin{array}{l}2 \\
1\end{array}$ & $\begin{array}{l}12 \\
19\end{array}$ & $\begin{array}{r}11 \\
6\end{array}$ & $\begin{array}{l}2 \\
2\end{array}$ \\
\hline
\end{tabular}

\section{Discussion}

This study of patients with fairly severe mite-sensitive asthma failed to show any benefit from a course of tyrosineadsorbed $D$ pteronyssinus vaccine. The overall incidence of local reactions-that is, swelling and itching-was higher in the placebo group, while general reactions-wheezing and dyspnoea -occurred within 48 hours of the injection in both groups.

Possibly our failure to show any benefit in asthmatics sensitive to house dust mite was due to the low strength of the vaccine but 400 Noon units was the highest strength available. D'Souza et $a l^{10}$ used a vaccine three times stronger than the commercially available aqueous extract, and some of their mite-sensitive patients benefited from the desensitisation. No subgroup of our patients benefited-for example, those with positive skin and nasal challenge responses to weak solutions of $D$ pteronyssinus extract showed no greater improvement in airways obstruction than those on placebo.

We thank Messrs Bencard for supplying the vaccine, Miss Jackie Urwin for statistical analysis, and Mrs Leys, Mrs MacAulay, and $\mathrm{Mr}$ David McKenzie for technical help.

Requests for reprints should be addressed to Dr K N V Palmer, University Department of Medicine, Foresterhill, Aberdeen AB9 2ZD.

\section{References}

${ }^{1}$ Voorhorst, R, Spieksma-Boezeman, M I A, and Spieksma, F T M, Allergie und Asthma, 1964, 10, 329

2 Pepys, J, Chan, M, and Hargreave, F E, Lancet, 1968, 1, 1270.

${ }^{3}$ Maunsell, K, Hughes, A M, and Wraith, D C, Practitioner, 1970, 205, 779.

${ }^{4}$ McAllen, M K, Assem, E S K, and Maunsell, K, British Medical fournal, 1970, 2, 501.

${ }^{5}$ Rao, V R M, et al, Clinical Allergy, 1975, 5, 209.

${ }^{6}$ British Thoracic and Tuberculosis Association, British Medical fournal, 1968, 3, 774.

' Aas, K, Acta Paediatrica Scandinavica, 1971, 60, 264.

${ }^{8}$ Maunsell, K, Wraith, D G, and Hughes, A M, Lancet, 1971, 1, 967

${ }^{9}$ Smith, A P, British Medical fournal, 1971, 4, 204.

10 D'Souza, M F, et al, Clinical Allergy, 1973, 3, 177.

\title{
SHORT REPORTS
}

\section{Quinaband-induced thrombocytopenic purpura in a patient with myxoedema coma}

Topical application of quinine analogues, unlike oral administration, has only once been reported to have caused thrombocytopenia. ${ }^{1}$ It occurred after one month's treatment with a hydrocortisonehydroxyquinoline cream and responded to prednisone. I report a further such episode that occurred after applying Quinaband dressings. The case highlights the severe systemic reactions that may follow the use of such a seemingly innocuous preparation. Quinaband contains zinc oxide paste $9 \cdot 25^{\circ} \%$, chloroiodohydroxyquinoline $1{ }^{\circ}$, calamine $5.75^{\circ} \mathrm{o}$, gum acacia $18.5^{\circ} \mathrm{o}$, boric acid $2^{\circ} \%$, glycerin $27^{\circ} \mathrm{o}$, prophyl hydroxybenzoate $0.0625^{\circ}{ }_{0}$, and water to $100^{\circ}{ }_{0}^{\circ}$.

\section{Case report}

A 68-year-old woman had attended another hospital for eight years for varicose ulcers and myxoedema. She took her thyroxine haphazardly and was admitted to this hospital in November 1974 in a confused state. This soon improved when she took her thyroxine regularly.

On 12 November 1975 she was readmitted for surgical treatment of extensive bilateral deep leg ulcers (right $17 \times 11 \mathrm{~cm}$, left $19 \times 20 \mathrm{~cm}$ ). She was found to have slow mental responses, was pale, and looked myxoedematous with a hoarse voice and dry skin. Her pulse rate was $60 / \mathrm{min}$ and regular, and her blood pressure $80 / 50 \mathrm{~mm} \mathrm{Hg}$. She was treated with her usual thyroxine, Multivite, and ferrous sulphate tablets, and Quinaband dressings were applied to the legs. She became drowsy and, five days after admission, lapsed into coma, her temperature dropping to $32.2^{\circ} \mathrm{C}$ and her pulse rate to $40 / \mathrm{min}$ Myxoedema coma was diagnosed and confirmed by a serum thyroxine of $10 \mathrm{nmol}(7.8 \mu \mathrm{g}) / 1$ (normal $60-160 \mathrm{nmol}(47-124 \mu \mathrm{g}) / \mathrm{l}$ ), a serum triiodothyronine of $0.5 \mathrm{nmol}(0.3 \mu \mathrm{g}) / 1$ (normal $1.4-3.0 \mathrm{nmol}(0.9-2.0 \mu \mathrm{g}) / \mathrm{l})$, and a serum thyrotrophin-stimulating hormone level of $45 \mathrm{mU} / 1$ (normal up to
$5 \mathrm{mU} / 1)$. Serum cortisol was normal. $X$-ray films of the chest showed basal consolidation, and the sputum grew Staphylococcus aureus.

She was treated with triiodothyronine $20 \mu \mathrm{g}$ daily, intravenous hydrocortisone $100 \mathrm{mg}$ six-hourly, and intramuscular ampicillin and flucloxacillin. Her heart was monitored, and her body temperature rose gradually. Her platelet count fell, however (see figure), and purpura was noted on the chest. She was transfused with 2 units of packed cells but her platelet count continued to fall, and on 23 November haematuria and nose bleeds occurred. Despite the adverse haematological picture her general condition improved, and she had regained consciousness on 21 November and could take her treatment by mouth.

Further investigation on 23 November showed normal prothrombin and bleeding times and normal levels of fibrinogen degradation products. Marrow biopsy showed plentiful megakaryocytes but poor platelet formation. Bilirubin

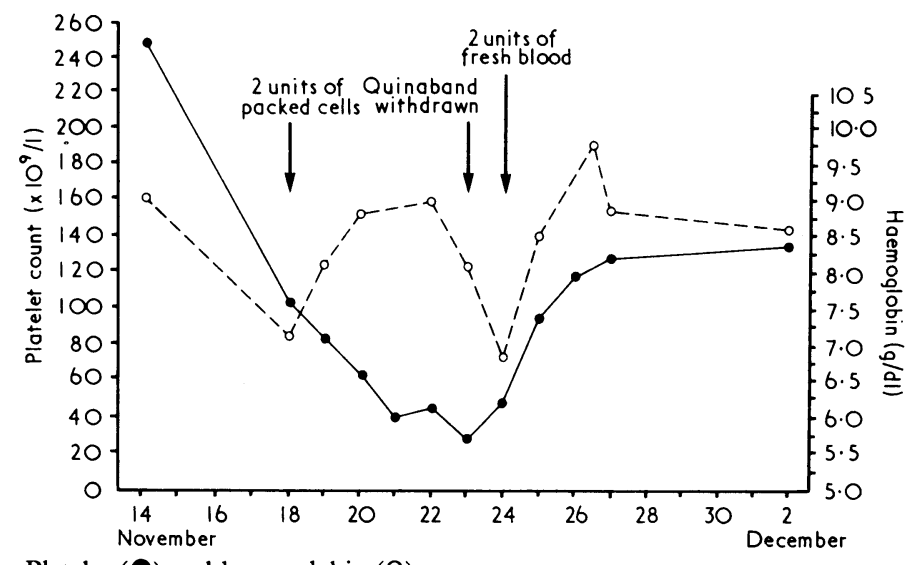

Platelet (O) and haemoglobin $(O)$ responses to treatment.

Conversion: SI to traditional units-Platelet count: $20 \times 10^{9} / 1=20000 / \mathrm{mm}^{3}$. 
and liver enzymes were normal. Patch tests for Quinaband gave negative results. Application of Quinaband was stopped, and on 24 November 2 units of fresh blood produced a rapid rise in platelet count, which subsequently returned to normal values. The patient made an excellent recovery and remained euthyroid, though the leg ulcers posed considerable problems.

\section{Comment}

The fall in platelets and haemoglobin coincided with the application of Quinaband, and these values rose when the dressings were withdrawn (albeit aided by transfusion), suggesting a causal mechanism. The large, deep ulcers allowed considerable absorption of the quininelike agents in the dressings and presumably led to the formation of platelet antibodies and hence thrombocytopenia. The coma after five days on the patient's regular thyroxine treatment is interesting. Firstly, action of L-thyroxine does not occur till after the second week. Thirdly, the anaemia may have precipitated coma in an already grossly myxoedematous patient. Finally, a combination of any of these three factors may have occurred.

The hypothermia may have been a defence mechanism to reduce the metabolic rate and counter the increased demands of the high-output state brought on by anaemia.

I thank Dr A L Wyman for invaluable help and criticism; Professor J Lee and Dr Nigel Huston for their support; and the department of medical illustration for the figure.

${ }^{1}$ Committee on Safety of Medicines, personal communication.

ALI A KHALEELI, MB, MRCP, medical registrar she may not have actually ingested the tablets. Secondly, maximal

Charing Cross Hospital, London W6 8RF

to the right, and, although serial chest radiographs failed to show reaccumulation of fluid, there was progressive shrinkage of the right hemithorax. Needle biopsy of the pleura showed undifferentiated malignant cells invading muscle and fibrous tissue. His pain was satisfactorily relieved by a $\mathrm{Cl}$ cordotomy (Mr E R Hitchcock) and he died one month later.

At necropsy (Dr H M Gilmour) dense tumour tissue obliterated the right pleural cavity and totally encircled the right lung. The histological features were those of anaplastic carcinoma with a prominent fibrous stromal reaction. A nodule within the posterior basal segment of the right lower lobe showed similar histological appearances and this appeared to be the most likely primary site. Secondary deposits were also found in the peritoneum, pericardium, and tunica vaginalis of the right testis. No metastases were found in the brain and spinal cord.

\section{Discussion}

Apical carcinoma of the bronchus is a well-recognised cause of Horner's syndrome. Stanford ${ }^{4}$ has recently described two cases of pleural mesothelioma with interruption of sympathetic nerve supply to the ipsilateral arm. Conceivably these destructive phenomena could be preceded by a phase of local irritation causing sympathetic excitation. This appears to have been the course of events in this patient, and as intrathoracic malignant disease is common it is perhaps surprising that this particular complication has not been seen more frequently.

The author is grateful to Dr G J R McHardy for permission to report this case.

${ }^{1}$ Ellis, H, British fournal of Hospital Medicine, 1972, 7, 641.

2 Telford, E D, British Medical fournal, 1942, 2, 96.

${ }^{3}$ Pool, J L, fournal of Neurosurgery, 1956, 13, 111.

+ Stanford, F, British Fournal of Diseases of the Chest, 1976, 70, 134.

Department of Respiratory Diseases, City Hospital, Edinburgh EH10 5SB

W G MIDDLETON, BSC, MRCP, senior registrar

\section{Hypothermia and Wernicke's encephalopathy}

Any lesion of the sympathetic pathway may produce localised hyperhidrosis. ' : Unilateral thoracic hyperhidrosis is rare and appears to have been recorded only by Pool, ${ }^{3}$ as a consequence of an osteoma of the 10th dorsal vertebra. The case reported here illustrates that unilateral thoracic hyperhidrosis may complicate brnochial carcinoma.

\section{Case report}

A 52-year-old man was admitted to hospital with a six-week history of right-sided pleuritic chest pain associated with cough and breathlessness. These symptoms had persisted despite treatment with a broad-spectrum antibiotic. He was a cigarette smoker and worked as an operating theatre technician. He was afebrile with signs of a small right-sided pleural effusion, confirmed by a chest radiograph. The pleural fluid was amber and contained $98 \%$ lymphocytes. A pleural biopsy showed no diagnostic features. The appearances at bronchoscopy ( $\mathrm{Mr} \mathrm{R} \mathrm{J} \mathrm{M} \mathrm{McCormack)} \mathrm{were} \mathrm{normal.} \mathrm{A}$ Mantoux test (1/1000 tuberculin) was positive with $15 \mathrm{~mm}$ induration; white cell count was $8.4 \times 10^{9} / 1\left(8400 / \mathrm{mm}^{3}\right)$. The results of plasma protein electrophoresis and of tests for antinuclear and rheumatoid factors were all normal.

The provisional diagnosis was of tuberculous pleural effusion and he was started on rifampicin, $600 \mathrm{mg}$ daily; ethambutol, $1.2 \mathrm{~g}$ daily; and isoniazid, $300 \mathrm{mg}$ daily. Over the ensuing three months he continued to complain of right-sided chest pain and there was no further radiographic improvement. He was again bronchoscoped because the radiographic appearances were thought to represent collapse of the right lower lobe. Nevertheless, the appearances at bronchoscopy were again normal. Antituberculous chemotherapy was continued, and prednisolone was added.

Four months after presenting he complained of excessive sweating affecting the right arm, right side of the chest, and right side of the face. This occurred in paroxysms several times daily and was observed regularly during his subsequent readmission to the ward. During such an episode perspiration was visibly excessive over an area extending from the face to T10 level, and at all levels there was an abrupt cessation of sweating at the midline. During his final hospital admission his main complaint was of persistent right lower chest pain. Radiographs of the thoracic spine showed a thoracic scoliosis concave
Hypothermia is well known as a complication of alcoholism, but there are few reports of its association with Wernicke's encephalopathy. A case of Wernicke's encephalopathy in which hypothermia was the presenting feature is reported.

\section{Case report}

A 54-year-old woman was admitted on the evening of 24 December 1975 with a rectal temperature of $29 \cdot 5 \mathrm{C}$. The outdoor temperature that afternoon was about $4 \mathrm{C}$ and she had been lying, fully clothed, for not more than seven hours on an internal common stair. She was incapable of giving a history, but according to her relatives had been a heavy drinker for five years. She had been ataxic for some months, and one week before her admission she had been found cold and drowsy, but had recovered at home.

She was drowsy, obese, cold, and hyperventilating. She did not smell of stimuli. Cranial nerve function could not be tested fully. She was normotensive (blood pressure $140 / 80 \mathrm{~mm} \mathrm{Hg}$ ) with a regular pulse of $80 /$ minute. Emergency investigations showed hypokalaemia (serum potassium $2 \cdot 3$ $\mathrm{mmol}(\mathrm{mEq} / \mathrm{l})$, blood sugar of $16.4 \mathrm{mmol} / 1(295 \mathrm{mg} / 100 \mathrm{ml})$ and a compensated metabolic acidosis. She was given ampicillin, oral fluids, and potassium supplements and rewarmed passively. Thirty-six hours later her blood sugar had returned to normal and her oral temperature was $39.5^{\circ} \mathrm{C}$. She was conscious, but apathetic and hallucinated. Bilateral sixth nerve palsies, bilateral vertical nystagmus, peripheral neuropathy with bilateral foot-drop, and ataxia of all limbs were then obvious. Wernicke's encephalopathy was diagnosed and she was given intramuscular thiamine $100 \mathrm{mg}$ and intravenous parenterovite HP daily. She continued to have hallucinations for several days; as this resolved, severe memory impairment with confabulation became evident. The peripheral neuropathy improved very slowly; the ataxia persisted. In view of the Korsakoff's psychosis she was transferred to psychiatric care. alcohol, moved all four limbs spontaneously, and responded to painful 